\title{
Never the Twain Shall Meet? Integrating Chinese and Western Management Research
}

\section{Kwok Leung \\ City University of Hong Kong}

ABSTRACT This commentary offers several directions for the development of Chinese management research based on the penetrating analyses provided by Barney and Zhang (2009) and Whetten (2009). First and foremost, Chinese management researchers can develop novel, seminal ideas and theories that are not necessarily tied to the Chinese cultural context but are applicable in diverse cultural contexts. The success of this approach depends on the merit of the ideas and theories proposed. A fusion, or combined emic-etic approach, can also be attempted, which integrates elements from Western and indigenous theories. Finally, the synergistic approach involves a dynamic interplay of Chinese and Western management research, which will eventually lead to innovative, culture-general theories. This article argues that all three approaches should be emphasized in Chinese management research.

KEYWORDS Chinese management, combined emic-etic approach, indigenous research, synergistic approach

\section{INTRODUCTION}

Many people predict that China will emerge as an economic powerhouse by 2025, and it is indeed timely to forecast the trajectory of Chinese management research in the current take-off stage of the Chinese economy. We are fortunate to have two extremely thoughtful, penetrating analyses of the future of Chinese management research. As social scientists are more capable of explaining past events than predicting how the future will unfold, my commentary is intended to highlight a few critical issues that may shape the future of Chinese management research.

Barney and Zhang (2009) have identified two distinct paths for Chinese management research. The pursuit of a 'theory of Chinese management' involves, in essence, the application and refinement of Western theories in the Chinese context. The underlying epistemology is universalism, in that etic (culture-general) theories can be formulated and validated in diverse cultural contexts. In contrast, the pursuit of a 'Chinese theory of management' assumes that some Chinese phenom- 
ena can only be understood in terms of indigenous or emic constructs. They argue that this type of Chinese theory is unlikely to be applicable in other cultural contexts and, hence, does not appeal to researchers who have no inherent interest in Chinese management.

The contrast of an etic (a theory of Chinese management) and an emic (a Chinese theory of management) approach has been discussed and debated for several decades in cross-cultural psychology and anthropology (for recent renditions, see Tsui, 2004; Yang, 2000). Barney and Zhang have provided a lucid analysis of the pros and cons of these two approaches for Chinese management researchers who are perplexed by the two options. Drawing upon cross-cultural psychology and anthropology, I build on their analysis and propose that there are actually more than two approaches or options for Chinese management research.

\section{THREE MORE PATHS FOR CHINESE MANAGEMENT RESEARGH}

I propose that there are three additional paths for Chinese researchers to consider. The first path aims at the discovery of novel, seminal ideas and theories that are culture-general, which is the golden fleece of academic research. The second path involves a fusion, or combined emic-etic approach, which integrates elements from Western and indigenous theories. Finally, the synergistic approach involves a dynamic interplay of Chinese and Western management research, with the aim of developing innovative, culture-general theories.

\section{The Universal Appeal of Trail-Blazing Ideas}

Why didn't I think of that?

Thomas Henry Huxley, on Darwin's theory of evolution (Lesier, 2003)

Barney and Zhang argue that a Chinese theory of management (an emic theory) has little appeal outside China. However, both Barney and Zhang and Whetten recognize that management research in the US context is as emic as management research in any other context. The emic origin of American theories and the use of primarily American data to verify these theories do not deter American theorists from positing their theories as descriptions of universal human nature. In the cases of some theories, the evidence supports the claim of universality. Thus, there is no inherent reason why emic theories developed in the Chinese context (a Chinese theory of management) cannot become universal theories. To illustrate this argument, consider the knowledge framework proposed by Nonaka (Nonaka, 1994; Nonaka \& Takeuchi, 1995). Although his theorizing is primarily based on the study of Japanese firms, his theoretical framework has had a huge impact in the West. The 1995 book by Nonaka and Takeuchi has been cited more than 9,000 times, according to Google Scholar. 
There is, of course, no Chinese management theory that enjoys such status at this time, but this has much to do with the short history of Chinese management research and nothing to do with the logical implausibility of Chinese theories emerging as universal theories. If a Chinese management researcher comes up with a truly trail-blazing idea and is able to marshal unequivocal evidence to substantiate it, the theoretical framework based on this idea may eventually enjoy worldwide recognition. The critical issue here is how to stand out in a competition of ideas. If we could assume a scientific community free of ethnocentrism, then whether the idea is conceived in a Chinese context and supported by Chinese data should not be important. Of course, the scientific community is not yet free of bias - it remains centered on Western culture and the English language - so Chinese ideas face extra challenges in gaining recognition in the global marketplace of ideas.

\section{Fusion: A Chinese-Western Theory of Management}

It does not matter if it is a yellow cat or a black cat, as long as it catches mice. Deng Xiaoping (Nam, 1997: 1)

The pursuit of a Chinese theory of management, as argued by Barney and Zhang, is not conducive to international recognition and is likely to result in intellectual isolation from the rest of the world. One way to sidestep this predicament is to adopt a combined emic-etic approach (e.g., Berry, 1990; Brett, Tinsley, Janssens, Barsness, \& Lytle, 1997) or, to follow the language of Barney and Zhang, to develop a 'Chinese-Western theory of management'.

Why do we need a theory? The answer is simple: a good theory helps us to accurately understand and predict events and phenomena. The more precisely a theory helps us to understand and predict an event, the better the theory. When researchers are confronted with a management phenomenon in the Chinese context, they should muster all the relevant constructs to formulate the best theoretical model possible. Borrowing from Deng Xiaoping, if you have a serious mouse problem, you let out all the cats you have, be they Chinese or Western, to eradicate the mice. Consider the research on paternalistic leadership discussed by Barney and Zhang (2009) and by Cheng, Wang and Huang (2009). A combined emic-etic approach would call for the inclusion of leadership concepts from the West, such as transformational leadership, as well as concepts associated with paternalistic leadership to understand and predict leadership phenomena in China (for such a study, see Cheng, Chou, Wu, Huang, \& Farh, 2004). A leadership theory derived from this theoretical fusion is likely to generate the most accurate and comprchensive description and prediction of the leadership phenomena in China.

I argue that this type of theoretical fusion has an important role to play in the international academic arena. Leadership theories developed in the West are 
shaped by its cultural and institutional forces, which tend to overlook any constructs and phenomena that are not salient in the Western context. While paternalistic leadership may not be salient in the West, elements of paternalistic leadership do exist. Theories of paternalistic leadership are likely to help Western managers understand the antecedents and consequences of paternalistic leadership in their settings (Pellegrini \& Scandura, 2008).

Although the combined emic-etic approach is rarely attempted in management research, there are successful cases in psychology, which have drawn worldwide attention and enriched Western theories. For instance, Hofstede (1980) identified four cultural dimensions in his classic research on IBM employees. Chinese Cultural Connection (1987), a team led by Michael Bond, identified a new dimension based on Chinese values, termed Confucian dynamism, which was predictive of economic growth. Hofstede (2001) subsequently relabeled this dimension as short-term vs. long-term orientation. Another example comes from the research on Chinese personality (Cheung, Cheung, Leung, Ward, \& Leong, 2003), which has uncovered a relational personality construct, termed interpersonal relatedness, that is also identifiable in the West but has been overlooked by Western researchers. This relational personality construct may represent an important omission in Western personality theories and may eventually prove to be important around the world.

\section{Dynamic Interplay between Chinese and Western Perspectives}

There is a tide in the affairs of men

Which, taken at the flood, leads on to fortune;

Omitted, all the voyage of their life

Is bound in shallows and in miseries.

William Shakespeare, Fulius Caesar (1988: 129)

Traditionally, emic and etic approaches are seen as independent research pathways, which is also the position maintained by Barney and Zhang. The combined emic-etic approached outlined above is intended to break the barrier between these two perspectives, but there is a limitation in that its integration of emic and etic perspectives is static. Morris, Leung, Ames, and Lickel (1999) argue that theories can evolve over time in response to both kinds of research. To augment the static nature of the combined emic-etic approach, Morris et al. (1999) proposed a dynamic, iterative interplay between an emic and an etic perspective for the development of universal theories. Briefly put, emic research can offer new insight for refining and expanding etic theories. In return, etic research can highlight theoretical constructs and processes that are important in a given culture but that are missed by emic researchers. A constant exchange and mutual stimulation can improve both emic and etic theories over time, giving rise to their integration and the formulation of universal theories. 
The proposal of Morris et al. (1999) shares some common features with the fourfold typology of cross-context theoretical contributions described by Whetten (2009). In his typology, context-sensitive contributions of organizational theory refer to the examination of whether a certain theory can be applied in a different cultural context. The confirmation of this theory would offer some new insight to researchers from this cultural context. In context-sensitive contributions to organizational theory, the examination of a theory in a culture different from its culture of origin results in the modification and refinement of the theory. In contributions of context-effects theory, contextual elements become an integral part of a theory. Finally, in contributions to context-effects theory, cultural context provides a source of new insight for improving context-effects theories.

While there are nuanced differences in these four types of theoretical contributions proposed by Whetten, they are primarily concerned with the applicability of Western theories in a Chinese context, with the ultimate aim to develop culturegeneral or universal theories based on these Western theories. Arguably, these four types of contribution represent different genres of the etic approach, and a simple way to summarize this fourfold typology is that management research in diverse cultural contexts is able to improve and broaden Western management theories (for similar arguments, see Triandis, 1980; Van de Vijver \& Leung, 1997). Management research in the Chinese context is seen as an important way to enrich Western theories and improve their generalizability.

Along with Whetten's context-sensitive contributions of organizational theory, the approach promulgated by Morris et al. (1999) also recognizes the possibility that the etic approach can offer insight to emic research. Furthermore, the examination of an etic theory in diverse cultural contexts can contribute to its extension and refinement, which Whetten has lucidly delineated in the other types of contributions. In fact, these three other types can be regarded as a systematic classification of various forms of the combined emic-etic approaches described before, which is portrayed on the right-hand side of Figure 1.

What is less emphasized in Whetten's analysis is the dynamic interplay between emic and etic approaches, a key feature of the approach of Morris et al. (1999). It is entirely possible that emic research can lead to the creation of novel etic theories, which, in turn, highlight new areas for emic enquiry. This argument, portrayed in the left-hand side of Figure 1, suggests that a Chinese theory of management (an emic theory) as described by Barney and Zhang can, in fact, give rise to a universal management theory. Specifically, a researcher may be intrigued by some uniquely Chinese phenomena and develop what Barney and Zhang call a Chinese theory of management. An important feature of the Morris et al. approach is that the formulation of this emic theory needs to take into account relevant Western theories in the initial stage of development as well as in subsequent refinements. The initial version of this Chinese theory may have limited applicability outside China, but subsequent refinements that broaden 
Figure I. Dynamic interplay between Chincse and Western perspectives (adapted from Morris et al., 1999)

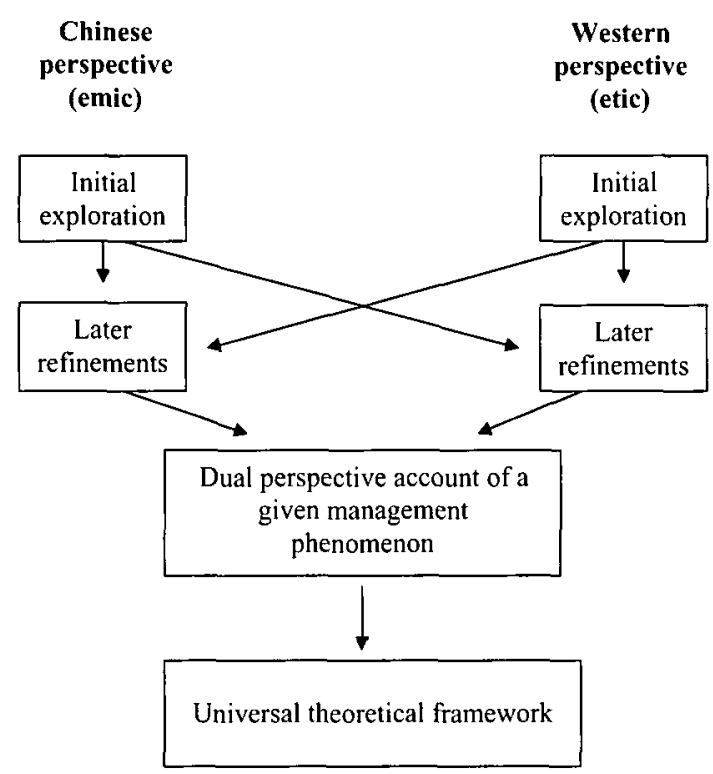

Note: In the current management literature, Chinese theories are assumed to be emic, whereas Western theories are assumed to be etic until proven otherwise. There is actually no logical reason why Chinese theories cannot be assumed to be etic at the onset.

the emic constructs into culture-general constructs may render this theory universal.

An example to illustrate this dynamic approach is the emic model of interpersonal harmony developed by myself and a few colleagues (Leung, Koch, \& Lu, 2002). This Chinese model has been examined in China as well as in Australia (Leung, Brew, Zhang, \& Zhang, unpublished paper: 'Harmony and conflict: A coss-cultural study in China and Australia', 2008), and an etic model that is based on this emic model but that also takes into account American models of conflict management has been formulated (Leung \& Brew, 2009). It is too early to tell if this general model, with its emic roots in Chinese culture, will eventually be developed into a truly universal model, but this program of research illustrates the potential of a dynamic interplay between emic and etic theorizing for transforming an emic model into an etic model.

\section{CONGLUSION}

Letting a hundred flowers blossom.

Chairman Mao Zedong (Barnett, 1967: 174)

The Chinese context provides a rich source for new constructs and phenomena (Leung, 2007; Tsui, 2006) and to exploit its potential fully, diverse approaches 
should be encouraged. Unfortunately, while diversity is a key to adaptiveness and long-term success, Chinese management research seems to be heading towards homogeneity (Tsui, 2007). The current zeitgeist in Chinese academic institutions emphasizes international recognition, which translates into mounting pressure on academics to publish in English journals, especially those in the USA (Leung, 2007). As both Cheng et al. (2009) and Zhao and Jiang (2009) observed, to maximize publication success, it is all too tempting for Chinese management researchers to pursue an incremental route by heralding the refinement of well-known Western management theories as the primary contributions of their work. Barney and Zhang are probably right that it is hard to pursue an integrative path that synthesizes Chinese and Western perspectives. Leong and Leung (2004) even argue that most Chinese researchers will succumb to strong institutional pressure and look to the West for a 'borrow with the intent to improve' approach as described by Whetten (2009: 49). The indigenous and integrative paths will remain the roads less traveled in the foresecable future.

It takes wisdom as well as courage to conduct indigenous and integrative research. Both types of research are in uncharted waters and few models and theories can guide the exploration. Worse still is that most reviewers of mainstream English language journals are lukewarm about these types of research because of the reviewers' emphasis on theory and the concomitant suspicion of novel ideas and inductive research (Hambrick, 2007). However, if Chinese management research is confined to only the extension of Western theories, its significance in the global marketplace of ideas will be moderate at best. Paradoxically, the more Chinese management researchers desire to publish in the best English language journals, the more they need to conform to current theories and the less likely they are able to break new ground and offer the world seminal concepts and theories. Perhaps when a few Chinese enterprises become true world leaders and widely respected, researchers around the world will begin to entertain the possibility that emic theories developed in the Chinese context can be potential candidates for universal theories. The day when an emic theory of Chinese management finally emerges as a global theory may mark the complete transformation of China from a populous country to an economic superpower.

A journey of a thousand miles starts from beneath one's feet.

Lao Zi (Lau, 2001: 95)

\section{NOTE}

This article originated as a commentary on the papers by Barney and Zhang and by Whetten in the 'MOR special symposium - Exploitation or exploration: The future of Chinese management research' session of the third biennial conference of the International Association for Chinese Management Research, Guangzhou, China, June 2008. 


\section{REFERENGES}

Barnett, D. 1967. Quotations from chairman Mao Tse-Tung. New York: Bantam Books.

Barney, J. B., \& Zhang, S. 2009. The future of Chinese management research: A theory of Chinese management versus a Chinese theory of management. Management and Organization Reviez, 5(1): 15-28.

Berry, J. W. 1990. Imposed etics, emics, and derived etics: Their conceptual and operational status in cross-cultural psychology. In T. N. Headland, K. L. Pike, \& M. Harris (Eds.), Emics and etics: The insider/outsider debate: 84-99. Newbury Park, CA: Sage.

Brett, J. M., Tinsley, C. H., Janssens, M., Barsness, Z. I., \& Lytle, A. L. 1997. New approaches to the study of culture in industrial/organizational psychology. In P. C. Earley \& M. Erez (Eds.), New perspectives on international industrial/organizational psychology: 75-129. San Francisco, CA: The New Lexington Press.

Cheng, B. S., Chou, L. F., Wu, T. Y., Huang, M. P., \& Farh, J. L. 2004. Paternalistic leadership and subordinate responses: Establishing a leadership model in Chinese organizations. Asian Joumal of Social Psychology, 7(1): 89-117.

Cheng, B.-S., Wang, A.-C., \& Huang, M.-P. 2009. The road more popular versus the road less travelled: An 'insider's' perspective of advancing Chinese management research. Management and Organization Revieze, 5(1): 91-105.

Cheung, F. M., Cheung, S. F., Leung, K., Ward, C., \& Leong, F. 2003. The English version of the Chinese personality assessment inventory. Journal of Cross-Cultural Psychology, 34(4): 433-452.

Chinese Cultural Connection. 1987. Chinese values and the search for culture-free dimensions of culture. Journal of Cross-Cultural Psychology, 18(2): 143-164.

Hambrick, D. C. 2007. The field of management's devotion to theory: Too much of a good thing? Academy of Management Joumal, 50(6): 1348-1352.

Hofstede, G. 1980. Culture's consequences: Intermational differences in zeork-related values. Beverly Hills, CA: Sage.

Hofstede, G. 2001. Culture's consequences: Comparing values, behaviors, institutions and organizations across nations. Thousand Oaks, CA: Sage.

Lau, D. C. 2001. Tao Te Ching. Hong Kong: The Chinese University Press.

Leong, F. T. L., \& Leung, K. 2004. Academic careers in Asia: A cross-cultural analysis. Joumal of Vocational Behavior, 64(2): 346-357.

Lesier, L. 2003. Darwin on morality. NeuroReviezw. [Cited 8 November 2008.] Available from URL: http://www.neuroreview.com/article4.htm

Leung, K. 2007. Asian social psychology: Achievements, threats, and opportunities. Asian Joumal of Social Psychology, 10(1): 8-15.

Leung, K., \& Brew, F. P. 2009. A cultural analysis of harmony and conflict: Towards an integrated model of conflict styles. In R. S. Wyer, Jr., C. Y. Chiu, \& Y. Y. Hong (Eds.), Problems and solutions in cross-cultural theory, research and application. New York: Psychology Press.

Leung, K., Koch, P., \& Lu, L. 2002. A dualistic model of harmony and its implications for conflict management in Asia. Asia Pacific Journal of Management, 19(2): 20I-220.

Morris, M. W., Leung, K., Ames, D., \& Lickel, B. 1999. Views from inside and outside: Integrating emic and etic insights about culture and justice judgment. Academy of Management Review, 24(4): 781-796.

Nam, K. H. 1997. Quotations from Deng Xiaoping. Hong Kong: Sub-culture Ltd.

Nonaka, I. 1994. A dynamic theory of organizational knowledge creation. Organization Science, $5(1): 14-37$.

Nonaka, I., \& Takeuchi, H. 1995. The knowledge-creating company. Oxford: Oxford University Press.

Pellegrini, E. K., \& Scandura, T. A. 2008. Paternalistic leadership: A review and agenda for future research. Journal of Management, 34(3): 566-593.

Shakespeare, W. 1988. Julius Caesar: Act 4, Scene 3, lines 218-224 (M. Spevack, Ed.). Cambridge: Cambridge University Press.

Triandis, H. C. 1980. Introduction to Handbook of Cross-Cultural Psychology. In H. C. Triandis \& W. W. Lambert (Eds.), Handbook of cross-cultural psychology, vol. 1: 1-14. Boston, MA: Allyn \& Bacon. 
Tsui, A. S. 2004. Contributing to global management knowledge: A case for high quality indigenous research. Asia Pacific Journal of Management, 21(4): 491-513.

Tsui, A. S. 2006. Contextualization in Chinese management research. Management and Organization Revieze, 2(1): 1-13.

Tsui, A. S. 2007. From homogenization to pluralism: International management research in the Academy and beyond. Academy of Management Joumal, 50(6): 1353-1364.

Van cle Vijver, F. J. R., \& Leung, K. 1997. Methods and data analysis for cross-cultural research. Thousand Oaks, CA: Sage.

Whetten, D. A. 2009. An examination of the interface between context and theory applied to the study of Chinese organizations. Management and Organization Revieze, 5(1): 29-55.

Yang, K. S. 2000. Monocultural and cross-cultural indigenous approaches: The royal road to the development of a balanced global psychology. Asian Journal of Social Psychology, 3(3): $241-263$.

Zhao, S., \& Jiang, C. 2009. Learning by doing: Emerging paths of Chinese management research. Management and Organization Revieze, 5(1): 107-119.

Kwok Leung (mgkleung@cityu.edu.hk), Ph.D., University of Illinois, Urbana-Champaign, is a chair professor of management at City University of Hong Kong. His research areas include justice and conflict, cross-cultural research methods, social axioms and international business. He is a senior editor of Management and Organization Review and the president-elect of the International Association for Cross-Cultural Psychology. He is a fellow of the Academy of International Business, the Academy of Intercultural Research and the Association for Psychological Science.

Manuscript received: September 16, 2008

Final version accepted: November 12, 2008

Accepted by: Anne S. Tsui 